\title{
Governance principles for robust and resilient coastal systems in the face of global change
}

\author{
John M. Anderies ${ }^{1}$ (D) . Olivier Barreteau ${ }^{2}$ \\ Received: 27 June 2019 / Accepted: 28 June 2019 / Published online: 18 July 2019 \\ (C) Springer-Verlag GmbH Germany, part of Springer Nature 2019
}

Coastal areas face special challenges resulting from global change. These challenges are related to three distinct features of coastal areas: concentration of environmental impacts, multiple thresholds, and high sensitivity to climate change. River networks and hydrological processes integrate the consequences of land use and human activities that take place over large areas and, as a result, concentrate their impacts in coastal areas. Coastal areas are characterized by numerous sensitive boundaries and thresholds, i.e., the land-water interface, the intersection of saline and freshwater environments, and constrained space for particular land use patterns. Hence, they are especially sensitive to climate change impacts: a small change in sea level has the potential to push the system beyond a critical threshold and induce radical change in the social-ecological system. Further, the stakes for decisionmaking are high: a relatively large proportion of the population lives in coastal areas, real estate is very valuable, they are often biodiversity hot spots, and are home to very productive agro-ecosystems. This creates a high potential for conflict across multiple user groups. Many policymakers are aware of this situation and generate adaptation plans at their jurisdictional levels. However, policymakers acting in their own jurisdiction may generate spillovers that modify evolution pathways of related social-ecological systems or constrain adaptive capacity of other policymakers operating in other jurisdictions. As a consequence, there are several warning signs of

John M. Anderies

m.anderies@asu.edu

Olivier Barreteau

olivier.barreteau@irstea.fr

1 School of Human Evolution and Social Change and School of Sustainability, Arizona State University, Tempe, AZ 85287, USA

2 UMR G-EAU, AgroParisTech, Cirad, IRD, IRSTEA, Montpellier SupAgro, Univ Montpellier, Montpellier, France maladaptation emerging in coastal areas either because of a lack of coordination between policy actors across jurisdictions, incomplete analysis of potential cascading effects in complex policy contexts thus generated, or both.

To better understand the situation in coastal settlements, analytical frameworks developed to analyze resilience or robustness of social-ecological systems may offer some capacity to identify potential causes of maladaptation. This special issue focuses on one such framework, the Robustness of Social-Ecological Systems Framework (Anderies et al. 2004; Anderies 2015). This Framework has been applied to three coastal case studies in the UK, France, and South Africa within the frame of the MAGIC collaborative project. ${ }^{1}$ The Robustness Framework is well suited for this study because it strongly emphasizes the concept of infrastructure, encompassing hard infrastructures particularly important in coastal settlements and its interaction with other critical natural, human, human-made, and social infrastructures. This emphasis fits well with the characteristics of coastal areas that encompass a large number of infrastructures that facilitate development, provide security, preserve local assets, and manage related SES that may both complement and compete with one another.

The Robustness Framework is used in the Special Issue in two ways. First, it is taken as an analytical tool that is applied to understand the critical feedback structures that underlie the dynamics of each of the case studies. Second, it is assumed that the knowledge so acquired could support policymaking processes by uncovering potential paths leading to maladaptive outcomes and suggesting possible actions to prevent them from occurring. In both usage modes, coastal SES are mapped onto categories of linkages between different key entities in the Robustness Framework: Users, Public Infrastructure Providers, Public Infrastructure, and Natural Infrastructure. "Users" include those people

\footnotetext{
${ }^{1}$ Multi-scale Adaptations to Global changes In Coastlines under Belmont Forum and G8 International Opportunities Fund (IOF).
} 
who derive benefit from these interacting infrastructures. "Public Infrastructure Providers" include those who make decisions about what shared infrastructure is provided. "Public Infrastructure" consists of the complex of those who work in government agencies and other organized community groups to produce and maintain shared infrastructure and the infrastructure itself. The "Natural Infrastructure," referred to as "Resources" in early versions of the Robustness Framework (Anderies et al. 2004), consists of the biophysical context that supports human activities. This mapping exercise sheds light on connections and critical processes that might otherwise go unseen. The second usage mode is based on the recognition that in complex systems, a mere clarification of feedback relationships in the first usage mode is typically not sufficient to generate effective policy change to prevent maladaptation. It is now recognized that inclusion of stakeholder involvement at all steps of policy cycle is essential (Tsoukias et al. 2013). Frameworks such as the Robustness Framework may then also provide a basis to organize participation and frame the discussion, in our case towards working on interdependencies through public and natural infrastructures.

This Special Issue contains five papers. Three of them are examples of analysis of coastal SES using the Robustness Framework (Guerbois et al. 2019; Naylor et al. 2019; Therville et al. 2018). The fourth is an example of using the Robustness Framework to design a tool for framing interactions in stakeholder workshops (Bonté et al. 2019). The fifth and last takes a step back and reflects on refining the framework itself on the basis of the experiences of its use by the researchers who applied it to each case study (Anderies et al. 2019). The refinement of the framework focuses on improving its suitability for conducting comparative analysis of regional-scale SES dominated by human-made infrastructures.

Naylor et al. (2019) explore a case study in Cornwall facing increasing numbers of major flood and erosion events. They focus jointly on flood and erosion protection policies and biodiversity conservation policies. Their use of the Robustness Framework in this context shows the connection between risks directly due to flooding and erosion (first-order risks) and organizational risks connected to organization reputation (second-order risks). When ignored, these relations may lead to maladaptation because they influence decisionmaking at regional levels and, as a consequence, frame capacity to adapt at local levels.

Therville et al. (2018) focus on the multiplicity of adaptation processes linked to coastal management and land use planning at diverse organization levels in Southern France. They connect the Robustness Framework with the Network of Adjacent Action Situations approach (McGinnis 2011) to demonstrate the intensification of cascading effects and cross-scale feedbacks with increasing tensions among land planning and coastal management policies due to various global change impacts in the region.

Guerbois et al. (2019) provide the third case study example in the Garden Route in South Africa with a question regarding the difficulties of ecosystem-based adaptation. Joining the Robustness Framework with common-pool resources ontologies such as Ostrom's Design Principles, they show that ecological infrastructures interact negatively with hard infrastructures due to weak institutions. From this example, they elaborate an ontology for policymakers and stakeholders to improve their coastal adaptation policies.

Bonté et al. (2019) address the issue of stakeholder engagement through the use of a "serious game." This term refers to games representing a specific region with its problems and potential policy solutions and is played with stakeholders and policy actors from that region. This is quite different from more general, abstract role-playing games, public good games, or common-pool resource games whose players have no attachment to the game context (e.g., undergraduate students and community members who participate in generalized games). Bonté et al. (2019) describe such a game designed on the basis of the French case study by Therville et al. (2018) using the Robustness Framework as a guide and incorporating the existence of interactions across scales. This game pushes participants to explore the consequences of the interdependencies inherent in their choices of infrastructures to adapt some sectoral policy in a given place. In doing so, they directly feel and learn potential consequences of these interdependencies, hopefully bringing this new knowledge and understanding to their future real-world policy choices.

Finally, Anderies et al. (2019) build on these examples to refine the Robustness Framework. They focus on better describing possible links between various actors and infrastructures as these links are the mechanism by which to represent interdependencies in real-world systems. Toward this end, they generate a list of verbs based on their collective experience with dozens of case studies of socialecological systems and from the three case studies included in this special issue. This verb list helps bound the range of possible representations of social-ecological systems within the Robustness Framework to reduce ambiguity, increase generalizability, and allow for more systematic semantic comparative analysis of case studies.

The papers in this special feature provide some examples of the added value of analytical frameworks such as the Robustness Framework to study the capacity of social-ecological, and more generally, coupled infrastructure systems to cope with change. However, the Robustness Framework and other tools like it are living tools. Experiences with their practical application have suggested a need to decrease 
ambiguity in definitions of relationships within frameworks and clearer instructions for their use if they are going to contribute to discussions of how complex policies can be tailored, negotiated, and made adaptive. The papers in this special feature hopefully provide clarity in the application of the Robustness Framework to understand how communities can adapt to global change at the regional scale.

Funding Information U.S. National Science Foundation (ICER1342933).

\section{References}

Anderies JM (2015) Understanding the dynamics of sustainable socialecological systems: human behavior, institutions, and regulatory feedback networks. Bull Math Biol 77(2):259-280. https://doi.org/ 10.1007/s11538-014-0030-z

Anderies JM, Janssen MA, Ostrom E (2004) A framework to analyze the robustness of social-ecological systems from an institutional perspective. Ecol Soc 9(1):18. http://www.ecologyandsociety.org/ vol9/iss 1/art18/

Anderies JM, Barreteau O, Brady U (2019) Refining the robustness of social-ecological systems framework for comparative analysis of coastal system adaptation to global change. Reg Environ Chang. https://doi.org/10.1007/s10113-019-01529-0

Bonté B., Therville C, Bousquet F, Abrami G, Dhenain S, Mathevet R (2019) Analyzing coastal coupled infrastructure systems through multi-scale serious games in Languedoc, France. Reg Environ Chang. https://doi.org/10.1007/s10113-019-01523-6

Guerbois C, Brady U, de Swardt AG, Fabricius C (2019) Nurturing ecosystem-based adaptations in South Africa's garden route: a common pool resource governance perspective. Reg Environ Chang https://doi.org/10.1007/s10113-019-01508-5

McGinnis MD (2011) Networks of adjacent action situations in polycentric governance. Policy Stud J 39(1):51-78. https://doi.org/10. 1111/j.1541-0072.2010.00396.x

Naylor L, Quinn T, Brown K, Brady U, Anderies JM (2019) A multiscale analysis of social-ecological system robustness and vulnerability in Cornwall, UK. Reg Environ Chang. https://doi.org/10. 1007/s10113-019-01523-6

Therville C, Brady U, Barreteau O, Bousquet F, Mathevet R, Dhenain S, Grelot F, Brémond P. (2018) Challenges for local adaptation when governance scales overlap. evidence from Languedoc, France. Reg Environ Chang. https://doi.org/10.1007/s10113-018$1427-2$

Tsoukias A, Montibeller G, Lucertini G, Belton V (2013) Policy analytics: an agenda for research and practice. EURO J Decision Process 1(1-2):115-134. https://doi.org/10.1007/s40070-013-0008-3

Publisher's note Springer Nature remains neutral with regard to jurisdictional claims in published maps and institutional affiliations. 